Marquette University

e-Publications@Marquette

Chemistry Faculty Research and Publications

Chemistry, Department of

6-26-2013

\title{
Allosteric Activation of the Par-6 PDZ Via a Partial Unfolding Transition
}

Dustin S. Whitney

Medical College of Wisconsin

Francis C. Peterson

Medical College of Wisconsin

Evgeni L. Kovrigin

Marquette University, evgueni.kovriguine@marquette.edu

Brian F. Volkman

Medical College of Wisconsin

Accepted version. Journal of the American Chemical Society, Vol. 135, No. 25 (June 26, 2013):

9377-9383. DOI. (C) 2013 American Chemical Society. Used with permission. 


\title{
Allosteric Activation of the Par-6 PDZ via a Partial Unfolding Transition
}

\author{
Dustin S. Witney \\ Department of Biochemistry, Medical College of Wisconsin, \\ Milwaukee, WI \\ Francis C. Peterson \\ Department of Biochemistry, Medical College of Wisconsin, \\ Milwaukee, WI \\ Evgenii L. Kovrigin \\ Chemistry Department, Marquette University, \\ Milwaukee, WI \\ Brian F. Volkman \\ Department of Biochemistry, Medical College of Wisconsin, \\ Milwaukee, WI
}




\section{Abstract}
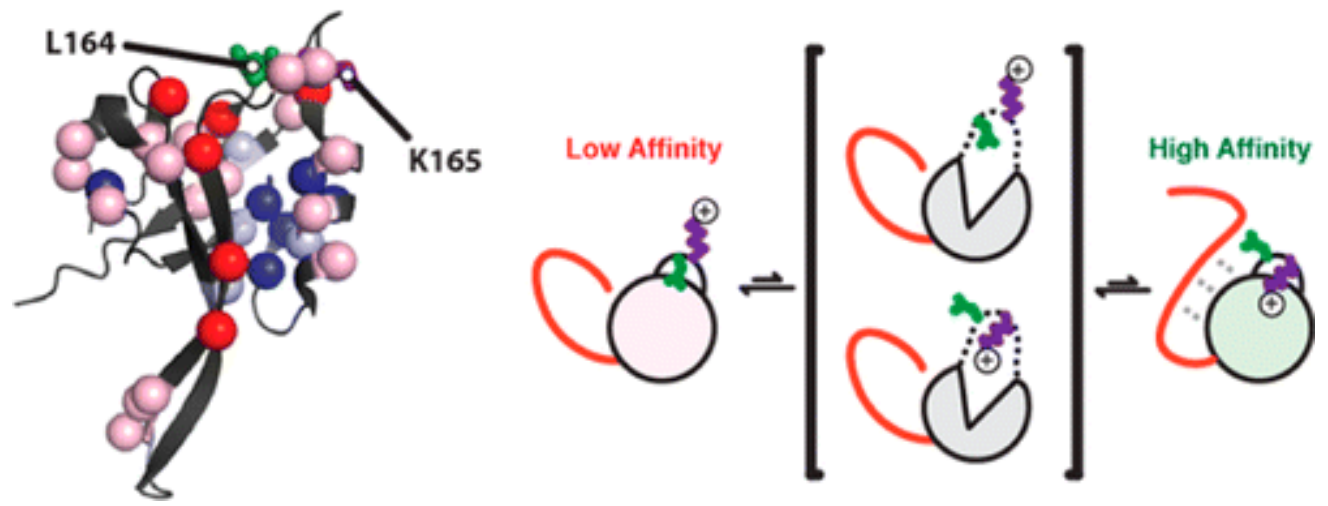

Proteins exist in a delicate balance between the native and unfolded states, where thermodynamic stability may be sacrificed to attain the flexibility required for efficient catalysis, binding, or allosteric control. Partitiondefective 6 (Par-6) regulates the Par polarity complex by transmitting a GTPase signal through the Cdc42/Rac interaction binding PSD-95/Dlg/ZO-1 (CRIB-PDZ) module that alters PDZ ligand binding. Allosteric activation of the PDZ is achieved by local rearrangement of the L164 and K165 side chains to stabilize the interdomain CRIB:PDZ interface and reposition a conserved element of the ligand binding pocket. However, microsecond to millisecond dynamics measurements revealed that L164/K165 exchange requires a larger rearrangement than expected. The margin of thermodynamic stability for the PDZ domain is modest $(\sim 3 \mathrm{kcal} / \mathrm{mol})$ and further reduced by transient interactions with the disordered CRIB domain. Measurements of local structural stability revealed that tertiary contacts within the PDZ are disrupted by a partial unfolding transition that enables interconversion of the $L / K$ switch. The unexpected participation of partial PDZ unfolding in the allosteric mechanism of Par- 6 suggests that native-state unfolding may be essential for the function of other marginally stable proteins.

\section{Introduction}

Structural fluctuations in the native state of proteins are essential for biological function. ${ }^{2}$ As originally defined by Anfinsen and understood today, the native state is the most stable, kinetically accessible conformation. ${ }^{3}$ From a thermodynamic perspective, internal picosecond to millisecond dynamics within most globular domains are viewed as small excursions around the global minimum of the conformational energy landscape. ${ }^{4-7}$ However, a protein will populate all thermodynamically (and kinetically) accessible states according to the relative free energy of each conformation. The population of unfolded protein in the native state is usually assumed to be negligible. This assumption may be perfectly valid when the 
equilibrium population of unfolded protein is small: A protein with $\Delta G_{\text {fold }}=-5 \mathrm{kcal} / \mathrm{mol}$ is $99.97 \%$ folded. In contrast, when the free energy of folding $\left(\Delta G_{\text {fold }}\right)$ is marginal (e.g., $\left.-2 \mathrm{kcal} / \mathrm{mol}\right)$, a significant fraction of the protein is unfolded $(3.7 \%)$ at equilibrium at $25^{\circ} \mathrm{C}$. It follows that fluctuations in the native state of a marginally stable protein may include frequent excursions to the unfolded state, partially folded states, or specific folding intermediates. Small domains with unfolding intermediates are less rare than once thought, ${ }^{8-10}$ and we speculate that some proteins with a single, marginally stable fold might sample local minima in the conformational energy landscape to access structurally related but functionally distinct states.

The PSD-95/DIg/ZO-1 (PDZ) domain of partition-defective 6 (Par-6) is a prototypical example of an allosteric PDZ for which the folding landscape is uncharacterized. Par- 6 is a modular scaffold/signaling protein that mediates cell polarity in several biological contexts. ${ }^{11-14}$ An adjacent Cdc42/Rac interaction binding (CRIB) motif combines with the PDZ to form a module (CRIB-PDZ) that interacts with Cdc42, a small GTPase in the Rho subfamily. We recently demonstrated that the L164-K165 'dipeptide switch' is the only apparent conformational change in the PDZ upon Cdc42 binding. ${ }^{11}$ Rearrangement of the side chains of L164 and K165 increases affinity for a C-terminal PDZ ligand 10-fold by inserting the K165 side chain into the peptide binding cleft. In the absence of Cdc42-GTP the L164 side chain points into the PDZ core toward the ligand-binding pocket and K165 is solvent exposed. In this low-affinity conformation (L164 'in'/K165 'out') CRIB:PDZ interactions are weak and transient (Figure 1). To date, Par-6 is the only PDZ domain in which the carboxylate binding pocket is remodeled in order to regulate C-terminal ligand binding. 

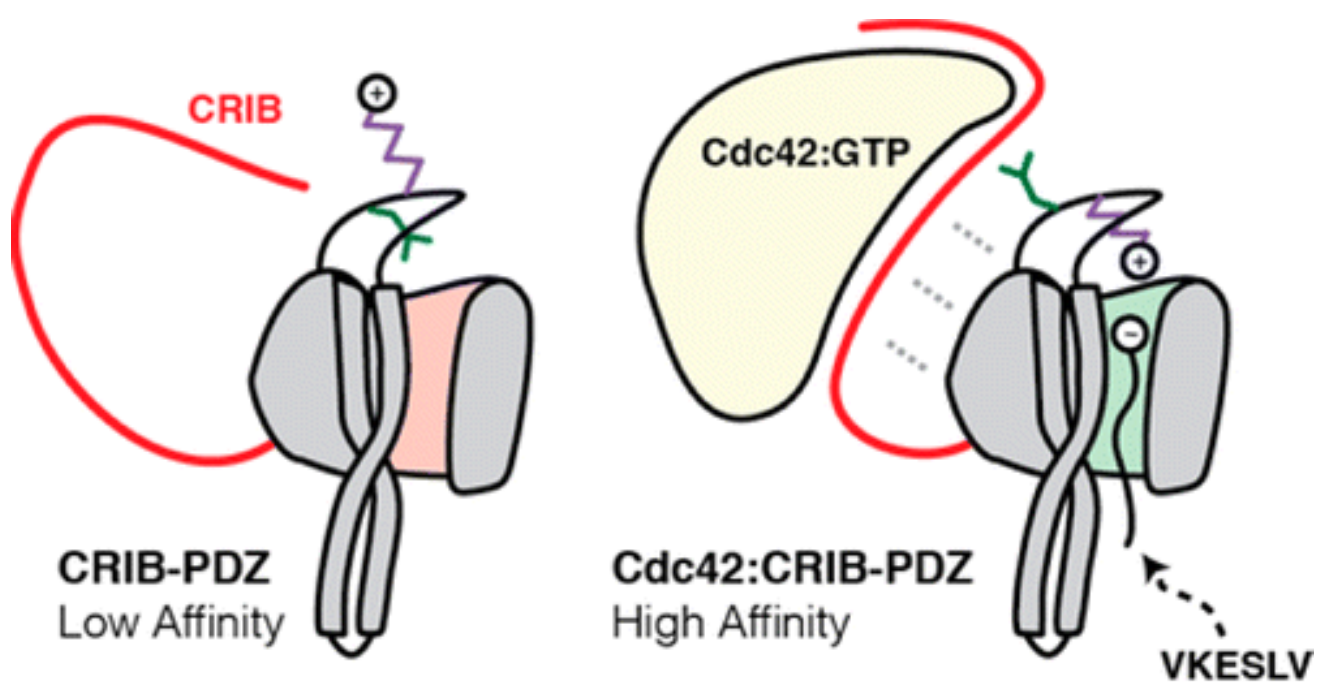

Figure 1. L/K switch governs C-terminal ligand binding affinity in the Par-6 CRIB-PDZ module. CRIB domain is colored red, PDZ domain is colored gray, and ligand binding cleft is colored red or green to signify low- or high-affinity state, respectively.

Our previous work suggested that the low- and high-affinity states of the CRIB-PDZ allosteric switch interconvert rapidly on the NMR chemical shift time scale. ${ }^{11}$ In the present study, we sought to measure the intrinsic rate of the dipeptide switch by ${ }^{15} \mathrm{~N}$ relaxation dispersion. Since switch interconversion scarcely alters PDZ structure we hypothesized that conformational exchange contributions $\left(R_{\mathrm{ex}}\right)$ would be localized to the immediate area of the switch itself. Instead, we found that dipeptide switching is linked to a domain-wide exchange event in the PDZ. The presence of unstructured CRIB residues $\mathrm{N}$ terminal to the PDZ destabilizes the native PDZ fold and increases access to an unfolding intermediate. Our results suggest that partial unfolding is required for allosteric regulation of the Par- 6 CRIB-PDZ module.

\section{Results}

Peptide Binding Flips the L/K Switch in Par-6 CRIB-PDZ Our previous work suggested that the L/K switch flips when a $C$ terminal peptide (VKESLV) binds the Par-6 PDZ, ${ }^{11}$ but this ligandinduced conformational change had not been directly detected. To monitor the conformational state of the dipeptide switch, we introduced a cysteine at position 164 within the L/K switch (CRIB$\mathrm{PDZ} \mathrm{Z}^{\mathrm{L} 164 \mathrm{C}}$ ) and conjugated a nitroxide radical-containing spin label (MTSL) to the side chain thiol. We estimated residue-specific

Journal of the American Chemical Society, Vol 135, No. 25 (June 26, 2013): pg. 9377-9383. DOI. This article is (c) American Chemical Society and permission has been granted for this version to appear in e-Publications@Marquette. American Chemical Society does not grant permission for this article to be further copied/distributed or hosted elsewhere without the express permission from American Chemical Society. 
paramagnetic relaxation enhancement (PRE) effects from ${ }^{1} \mathrm{H}-{ }^{15} \mathrm{~N}$ HSQC peak intensities in the absence and presence of VKESLV. Backbone amides exhibiting MTSL-induced broadening in the apo state are shown in Figure 2A,B (Table S1). With the exception of two CRIB residues, PREs fill and surround the PDZ binding pocket, indicating that the $\mathrm{C} 164$ side chain extends into the PDZ ligand binding cleft, equivalent to the position of L164 in the low-affinity state. Peptide binding altered the PRE pattern substantially (Figure 2C,D, Table S1). Significant PREs throughout the CRIB domain and one face of the PDZ domain describe a new set of contacts with the spin label away from the peptide binding cleft. For example, peptide binding eliminated all the PREs in the $\beta_{2}$ strand (G173, F174, Y175, I176) observed in the apo state. Taken together, these data indicate that the C164conjugated spin label evacuates the PDZ core to a solvent exposed position upon VKESLV binding, consistent with a ligand-induced rearrangement of the dipeptide switch from the low- to high-affinity PDZ conformation. ${ }^{11}$

A

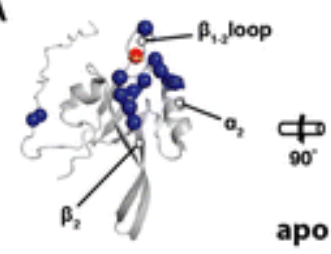

C

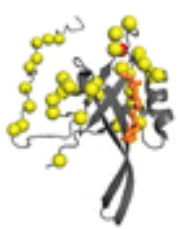

apo
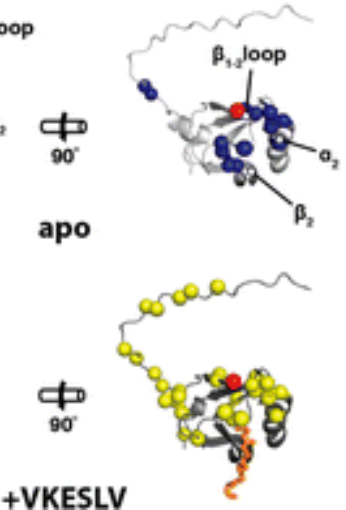

B
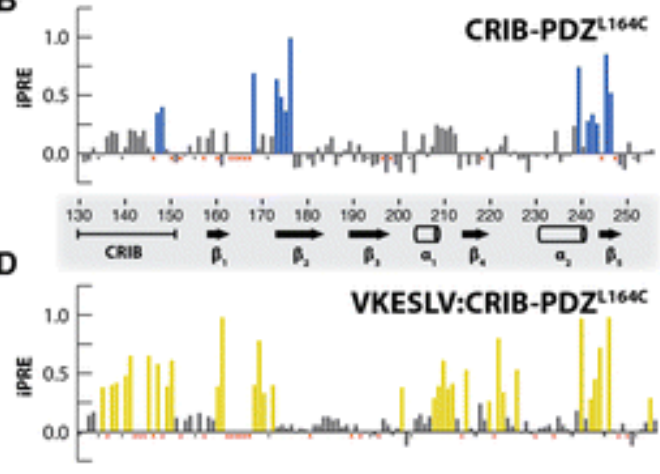

Figure 2. VKESLV binding flips the $L / K$ switch. PRE data for CRIB-PDZ ${ }^{L 164 C}$. (A) Blue spheres indicate broadened residues in the apo state. (B) iPRE (iPRE $=1-I^{\text {para }} / I^{\text {dia }}$ ) vs residue number for CRIB-PDZ ${ }^{L 164 C}$. Residues with significant iPRES values include: A147 and I148 of the CRIB domain, S168 of the $\beta_{1-2}$ loop; G174, F174, Y165, and I176 of the $\beta_{2}$ strand; and V239, N241, S242, and S243 of the $a_{2}$ helix, and L245 and I246 of the $\beta_{6}$ strand. (C) Yellow spheres indicate broadened residues in VKESLVbound state (VKESLV:CRIB-PDZ ${ }^{L 164 C}$ ratio $\geq 6: 1$ ), where blue bars indicate those with proximity to MTSL attached to $\mathrm{C} 164$ side chain. (D) iPRE vs residue number for CRIBPDZ ${ }^{164 C}$ and VKESLV:CRIB-PDZ ${ }^{L 164 C}$, where yellow bars indicate those with proximity to MTSL attached to C164 side chain. Significant iPREs for the CRIB domain (S135, S137, I138, H140, D141, V145, A147, I149, D150), $\beta_{1}$ strand (R160, V161), $\beta_{1-2}$ loop (S168, D169, K170, L172), $\beta_{2-3}$ hairpin (L200), $a_{1}$ helix region (E207, S208, T209, G210, L211, V214), $\beta_{4-5}$ region (I219, V221, N222, K229), a helix (N241, S242, S243), and $\beta_{6}$ strand (I246) highlight a surface of the PDZ domain distant from the binding cleft $(C, D)$. C164 is marked by a red sphere in $(A, C)$. Proline residues are marked with a black asterisk, and residues without a calculated iPRE value are marked 
with a red " $x$ ". A complete list of iPRE by residue for apo and VKESLV-bound states is located in Table S1.

\section{Internal Motions of the PDZ Reveal Global Exchange Throughout the Domain}

We previously detected conformational exchange broadening in CRIB-PDZ near the L/K switch ${ }^{11,12}$ and speculated that the low- and high-affinity states interconvert rapidly on the NMR chemical shift time scale. To define the intrinsic rate of $L / K$ switch interconversion, ${ }^{15} \mathrm{~N} \mathrm{R}_{2}$ dispersion was measured by (Carr-Purcell-Meiboom-Gill) (CPMG) experiments. ${ }^{15-17}$ Because $\mathrm{L} / \mathrm{K}$ switch flipping appeared to be a minor structural rearrangement, we expected limited $R_{2}$ dispersions localized to the switch region. Instead, significant $\mathrm{R}_{2}$ dispersions $\left(R_{\mathrm{ex}} \geq 1 \mathrm{~s}^{-1}\right)$ were detected at 32 sites in PDZ ${ }^{156-255}$ and 47 sites in CRIB-PDZ ${ }^{130-255}$ distributed across each protein (Figure 3A,B). Twenty-three significantly exchanging residues were common to both constructs (Figure 3C), suggesting these domain-wide transitions might be reporting on the same exchange event.
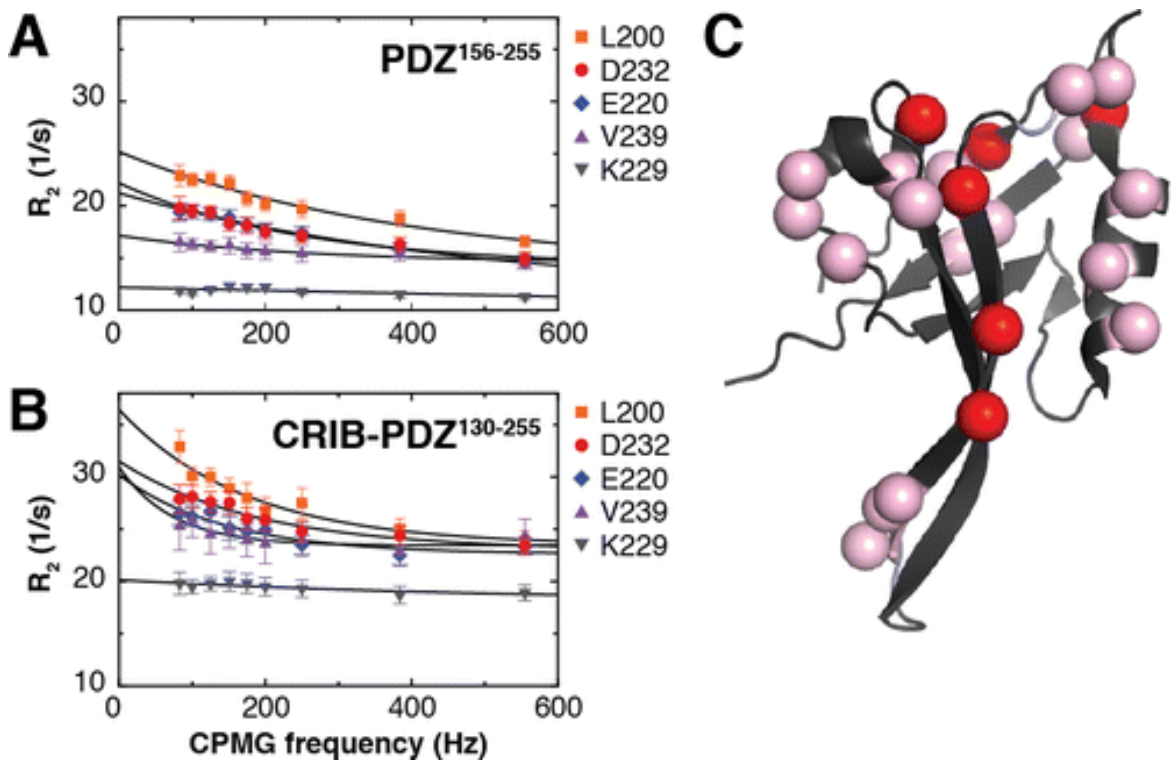

Figure $3 .{ }^{15} \mathrm{~N}$ relaxation dispersion reveals a domain-wide transition in apo $\mathrm{PDZ}^{156-255}$ and CRIB-PDZ ${ }^{130-255}$. Representative dispersion curves for several sites of $(A) P D Z^{156-}$ 255 and (B) CRIB-PDZ ${ }^{130-255}$ as well as sites that lack dispersion and possess a flat, featureless profile as a result. $1 / T_{c p}$ is the effective $B_{1}$ frequency in the CPMG experiment. (C) Pink spheres indicate residues with significant $\mu s-m s$ exchange for both PDZ ${ }^{156-255}$ and CRIB-PDZ ${ }^{130-255}$. Red spheres indicate residues with significant individual $\mu s-m s$ exchange and those globally fitted for both PDZ ${ }^{156-255}$ and CRIBPDZ ${ }^{130-255}$. Analysis proceeded as described previously. ${ }^{1}$

Journal of the American Chemical Society, Vol 135, No. 25 (June 26, 2013): pg. 9377-9383. DOI. This article is (c) American Chemical Society and permission has been granted for this version to appear in e-Publications@Marquette. American Chemical Society does not grant permission for this article to be further copied/distributed or hosted elsewhere without the express permission from American Chemical Society. 
Residues that exhibit similar $k_{\text {ex }}$ values in a folded domain are likely to report on a single conformational exchange process. ${ }^{4}$ To identify the dominant motional mode in each construct, ${ }^{15} \mathrm{~N}$ relaxation dispersion data were subjected to a global fitting process. ${ }^{17-19}$ Global fitting of 11 residues in PDZ ${ }^{156-255}$ and 16 residues for CRIB-PDZ ${ }^{130-255}$ yielded a rate $\left(k_{\mathrm{ex}}\right)$ of $\sim 1600 \mathrm{~s}^{-1}$ for each case (Table S2). Because these internal motions are in the fast exchange regime, population ratios $\left(p_{\mathrm{A}}, p_{\mathrm{B}}\right)$ and chemical shift differences $(\Delta \omega)$ are not reliable for direct comparison. ${ }^{17,19}$ However, similar $k_{\text {ex }}$ values for PDZ ${ }^{156-255}$ and CRIB-PDZ ${ }^{130-255}$ indicate that the CRIB does not measurably alter intrinsic conformational exchange kinetics in the PDZ. CRIB-PDZ ${ }^{130-255}$ residues participating in concerted motion are found adjacent to the PDZ ligand-binding cleft (169, 174, 177, 232, and 243) near the CRIB:PDZ interface $(161,162,243$, and 247) and distributed throughout the PDZ domain $(179,187,213,216$, and 217 are all $>10$ $\AA$ from the ligand-binding cleft). PDZ ${ }^{156-255}$ residues participating in similar motions are located in the PDZ ligand binding cleft $(174,177$, and 235) and throughout the domain (179, 180, 188, 204, 207, and 220), but only one residue (162) is present at the CRIB:PDZ interface. Six residues $(162,174,177,179,204$, and 243) are common to the globally fitted populations of both constructs, and they cluster in or adjacent to the ligand-binding cleft of the PDZ, with four of those located in the $\beta_{2-3}$ finger of the domain (Figure $3 \mathrm{C}$ ). Detected motions in PDZ ${ }^{156-255}$ and CRIB-PDZ ${ }^{130-255}$ are likely to be a similar exchange event intrinsic to the PDZ and modified by the CRIB domain.

\section{Par-6 PDZ Does Not Unfold by a Simple Two-State Mechanism}

Given the domain-wide nature of detected exchange in $\mathrm{PDZ}^{156-}$ 255 and CRIB-PDZ ${ }^{130-255}$, we speculated that measured $k_{\text {ex }}$ in the 1600 $\mathrm{S}^{-1}$ range may report on an unfolding transition. ${ }^{20,21}$ As a result, we utilized single-jump stopped-flow kinetic folding measurements by monitoring fluorescence emission of Tyr 175 to determine folding and unfolding rates for PDZ ${ }^{156-255}$ and CRIB-PDZ ${ }^{130-255} .^{22,23}$ In a simple twostate protein folding mechanism, fluorescence-based kinetic folding curves can be fit to a single exponential, and both arms of the resultant chevron plot exhibit a linear dependence on denaturant concentration. ${ }^{24-26}$ The sum of folding $\left(k_{\mathrm{f}}\right)$ and unfolding $\left(k_{\mathrm{u}}\right)$ rate 
constants will be equal to the $k_{\text {ex }}$ determined from ${ }^{15} \mathrm{~N}$ dispersion data if they report on the same behavior. Both PDZ ${ }^{156-255}$ and CRIB-PDZ ${ }^{130-}$ 255 kinetic stop-flow chevrons displayed nonlinearity ("chevron rollover") in the unfolding arm (Figure 4A), however. Importantly, estimations of folding rates assuming a simple two-state folding mechanism yielded rate constants significantly below the measured $k_{\text {ex }}$ value $\left(k_{\mathrm{f}}+k_{\mathrm{u}}=65 \mathrm{~s}^{-1}\right)$, indicating that global unfolding is far too slow a process to account for detected exchange in the PDZ.
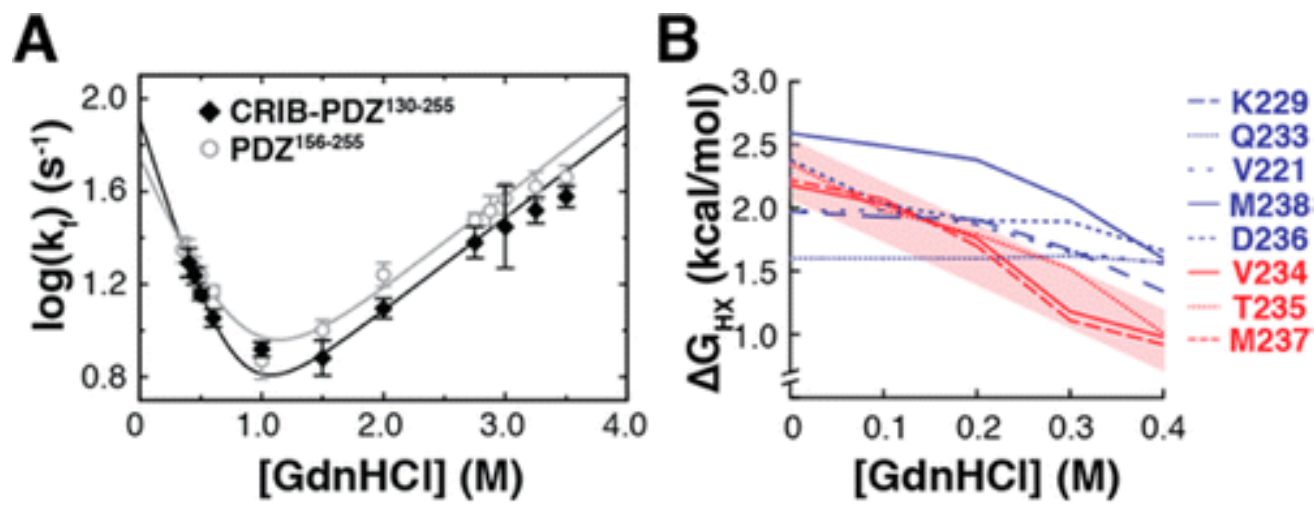

Figure 4. An intermediate is detectable in Par-6 unfolding. (A) Single-jump stoppedflow chevron plots for CRIB-PDZ130-255 (black diamonds) and PDZ ${ }^{156-255}$ (gray circles). Both chevrons display slight rollover in the unfolding arm. Nonlinearly fitted two-state folding equations are shown with black and gray lines for CRIB-PDZ ${ }^{130-255}$ and PDZ ${ }^{156-}$ 255 , respectively. (B) ${ }^{1} \mathrm{H}-2 \mathrm{D}$ exchange vs $[\mathrm{GnHCl}]$ graph showing CRIB-PDZ ${ }^{130-255}$ residues. $\mathrm{V} 234, \mathrm{~T} 235$, and $\mathrm{M} 237$ respond linearly to low $[\mathrm{GnHCl}]$, indicating their proximity to the region disrupted upon formation of the folding intermediate, and are colored red. All other residues are colored blue.

For Par-6 PDZ, chevron rollover in the unfolding arm is diagnostic of at least one unfolding intermediate in which the first transition state (TS1) has a higher energy barrier than the second (TS2), which is destabilized by addition of denaturant, causing an alteration in the rate-limiting step of protein unfolding. ${ }^{24,27,28}$ Earlier reports indicate that PDZ domains do not fold by a two-state mechanism, but instead sample at least one high-energy, on-pathway unfolding intermediate that is a feature of the PDZ domain family, ${ }^{5,28-30}$ consistent with our findings. 


\section{A Partial Unfolding Intermediate Is Detectable in CRIB- $P D Z^{130-255}$}

Unfolding intermediates are detectable in deuterium exchange experiments serially repeated at increasing levels of denaturant. ${ }^{31,32}$ Amide protons sensitive to partial unfolding excursions display linear dependence of $\Delta G_{\mathrm{HX}}$ on denaturant concentration, whereas unaffected residues remain resistant to low denaturant levels and local effects govern their $\Delta G_{H X}$ values. ${ }^{31,33}$ Divergent responses of intermediatesensitive and -insensitive residues persist until denaturant stabilizes the unfolded state, at which point $\Delta G_{H X}$ values cluster at a similar guanidine-driven global unfolding rate. $8,30,34$ We measured solvent exchange in CRIB-PDZ ${ }^{130-255}$ at $0,0.1,0.2,0.3$, and $0.4 \mathrm{M}$ guanidine $\mathrm{HCl}$ at $10^{\circ} \mathrm{C}$. Multiple responses are visible in CRIB-PDZ ${ }^{130-255}$, demonstrating the presence of at least one unfolding intermediate (Figure 4B, Table S4). Residues 234, 235, and 237 display a linear response to denaturant, whereas 221, 229, 233, 236, and 238 are insensitive to low levels of guanidine. These data are in agreement with the chevron rollover detected in kinetic folding measurements and confirm the presence of an unfolding intermediate in CRIB-PDZ ${ }^{130-255}$.

\section{Flexible CRIB Destabilizes the PDZ Domain}

Previously, we reported a small yet significant decrease of VKESLV binding affinity upon removal of the CRIB domain, ${ }^{11}$ and we speculated that transient CRIB-mediated stabilization of the PDZ domain and ligand binding pocket was responsible.

We collected native ${ }^{1} \mathrm{H}-{ }^{2} \mathrm{D}$ exchange data for $\mathrm{PDZ} \mathrm{Z}^{156-255}$ and CRIB-PDZ ${ }^{130-255}$ to monitor the effect of CRIB residues on the PDZ domain. Strikingly, protection factors were higher on average in $\mathrm{PDZ}^{156-255}$ than CRIB-PDZ ${ }^{130-255}\left(\log P_{\text {ave }}{ }^{\mathrm{PDZ}}=1.78, \log P_{\text {ave }}{ }^{\mathrm{CRIB}-\mathrm{PDZ}}=\right.$ 1.36), indicating a more rigid PDZ upon CRIB removal (Figure $5 A, B$ ). Free energies of unfolding $\left(\Delta G_{\mathrm{HX}}\right)$ may be calculated from fitted amide solvent exchange constants, ${ }^{32,35}$ and the largest calculated $\Delta G_{\mathrm{HX}}$ value from a protein reflects its global unfolding energy. ${ }^{30} \Delta G_{\mathrm{HX}}$ values were higher for PDZ ${ }^{156-255}\left(\Delta G_{\mathrm{HX}}{ }^{\mathrm{PDZ}}=3.4 \pm 0.2 \mathrm{kcal} / \mathrm{mol}\right)$ than CRIB-PDZ ${ }^{130-}$ ${ }^{255}\left(\Delta G_{\mathrm{HX}}{ }^{\mathrm{CRIB}-\mathrm{PDZ}}=2.9 \pm 0.5 \mathrm{kcal} / \mathrm{mol}\right)$, suggesting that the CRIB domain destabilizes the PDZ fold in CRIB-PDZ ${ }^{130-255}$. 
A
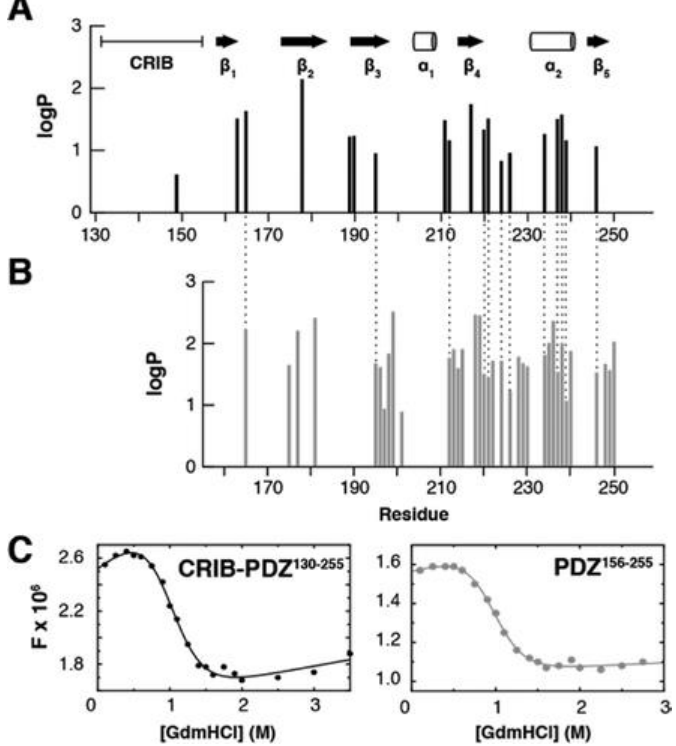

Figure 5. Par- 6 CRIB destabilizes the PDZ. Native ${ }^{1} \mathrm{H}-2 \mathrm{D}$ exchange data by residue for (A) CRIB-PDZ ${ }^{130-255}$ (black bars) and (B) PDZ ${ }^{156-255}$ (gray bars) at $25^{\circ} \mathrm{C}$. Dashed lines connect residues that exhibit significant protection factors $(\log P)$ for both proteins. (C) Equilibrium guanidine denaturation measurements with increasing concentrations of $\mathrm{GnHCl}$. Curves represent fitted functions used to determine $\Delta G_{\mathrm{GnHCl}}$. Open circles represent PDZ ${ }^{156-255}\left(\Delta G_{\mathrm{unf}}{ }^{\mathrm{PDZ}}=3.2 \pm 0.3 \mathrm{kcal} / \mathrm{mol}\right)$, and black diamonds signify CRIB-PDZ $^{130-255}\left(\Delta G_{\text {unf }}{ }^{\text {CRIB-PDZ }}=2.8 \pm 0.4 \mathrm{kcal} / \mathrm{mol}\right)$.

To confirm ${ }^{1} \mathrm{H}-{ }^{2} \mathrm{D}$ exchange results, we conducted fluorescencebased (Tyr 175) equilibrium unfolding measurements which showed that CRIB-PDZ ${ }^{130-255}$ is significantly less stable than PDZ ${ }^{156-255}$ $\left(\Delta G_{\text {unf }}{ }^{\text {CRIB-PDZ }}=2.8 \pm 0.4 \mathrm{kcal} / \mathrm{mol}, \Delta G_{\text {unf }}{ }^{\mathrm{PDZ}}=3.2 \pm 0.3 \mathrm{kcal} / \mathrm{mol}\right.$, $\left.P_{\text {comparison }}=0.013\right)($ Figure $5 \mathrm{C})$. A correlation plot comparing free energies determined from both guanidine equilibrium unfolding and native deuterium exchange supports this conclusion as well (Figure S2C). The relatively modest $\Delta G_{\text {unf }}$ values indicate that the Par-6 PDZ domain is marginally stable in general and by comparison to other PDZ domains. ${ }^{24,27,30}$ Transient CRIB-PDZ interactions which promote peptide binding $\left(K_{\mathrm{D}}, \mathrm{VKESLV}{ }^{\mathrm{CRIB}-\mathrm{PDZ}}=54 \pm 5 \mu \mathrm{M}, K_{\mathrm{D}, \mathrm{VKESLV}}{ }^{\mathrm{PDZ}}=72 \pm 5 \mu \mathrm{M}\right)$ also destabilize the PDZ domain by $\sim 0.4 \mathrm{kcal} / \mathrm{mol}$, demonstrating a PDZ destabilizing role for the free CRIB domain in Par-6. 


\section{Par-6 Peptide Binding of the PDZ Domain "Quenches" Exchange in Par-6 PDZ}

In the absence of a peptide ligand, the PDZ domain has a similar $\mu s-m s$ exchange profile regardless of whether the flexible CRIB is present (Figure $3 \mathrm{C}$ ). Peptide binding drives $\mathrm{L} / \mathrm{K}$ switch conversion to the high-affinity position, ${ }^{11}$ so we measured $\mathrm{R}_{2}$ relaxation dispersions in the presence of saturating amounts of ligand (VKESLV:protein > $6: 1)$. Nine residues possess significant conformational exchange $\left(R_{\mathrm{ex}} \geq\right.$ $1 \mathrm{~s}^{-1}$ ) in VKESLV:PDZ ${ }^{156-255}$ compared to 32 in apo PDZ ${ }^{156-255}$ (Figure $6 A)$. Five residues with significant dispersions in VKESLV:PDZ ${ }^{156-255}$ cluster near the CRIB:PDZ interface (157, 161, 212, 247, and 249), while no significant $R_{2}$ dispersions were found in the ligand binding pocket. No residues could be globally fitted in VKESLV:PDZ ${ }^{156-255}$ due to dissimilar rate constants, marking a large reduction in domain-wide exchange relative to apo PDZ ${ }^{156-255}$. In contrast, the $R_{\text {ex }}$ dispersion profile for VKESLV:CRIB-PDZ ${ }^{130-255}$ remained similar to CRIB-PDZ ${ }^{130-255}$ (Figure S1B). Global fitting of a subpopulation of residues sharing similar individual $k_{\text {ex }}$ values yielded 15 sites fit to an exchange rate $\left(k_{\mathrm{ex}}\right)$ of $1800 \pm 200 \mathrm{~s}^{-1}$, similar to apo CRIB-PDZ ${ }^{130-255}$ (Table S3B).
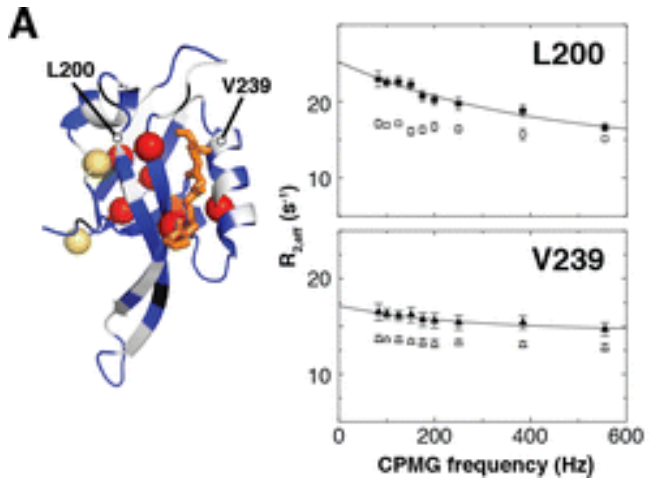

B

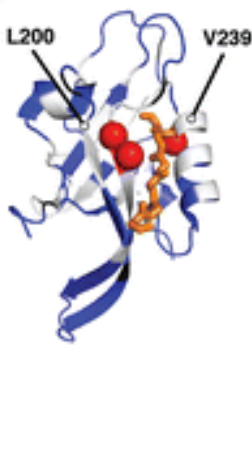

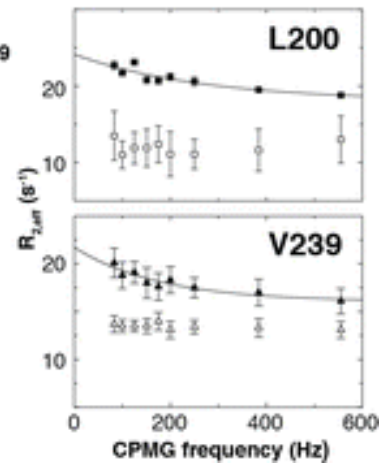

Figure 6. VKESLV binding quenches $R_{\mathrm{ex}}$ in PDZ ${ }^{156-255}$ and CRIB-PDZQ144C/L164C. Comparison of CPMG-based $R_{2}$ relaxation dispersion data for apo and VKESLV-bound PDZ ${ }^{156-255}$ and CRIB-PDZQ144C/L164C. White spheres represent quenched dispersions for VKESLV-bound Par- 6 relative to apo state, red spheres those that retain dispersions, and yellow for dispersions detected only in VKESLV:PDZ156-255 are indicated in for (A) VKESLV:PDZ ${ }^{156-255}$ and (B) VKESLV:CRIB-PDZQ144C/L164C. Nonexchanging residues are colored blue. Representative dispersion curves demonstrating reduced $R_{\text {ex }}$ upon VKESLV binding for both where black and white circles represent data for L200 in the apo and VKESLV-bound state, respectively. Black and white triangles represent data for V239 in the apo and VKESLV-bound state, respectively. VKESLV:protein ratio is $6: 1$. Analysis proceeded as described previously. ${ }^{1}$ 
To determine if $R_{\text {ex }}$ quenching could be replicated by a stabilized CRIB domain driving the high-affinity conformation of Par- 6 , we measured ${ }^{15} \mathrm{~N} R_{2}$ dispersion on a disulfide-stabilized CRIB-PDZ ${ }^{130-255}$ (CRIB-PDZQ144C/L164C, PDB entry: 2LC6), characterized previously. ${ }^{11}$ Only PDZ ligand binding pocket residues 174, 175, and 238 exhibited

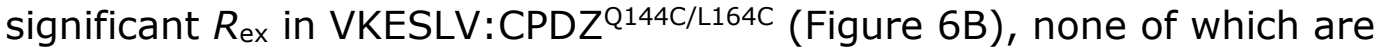
near the CRIB:PDZ interface, diagnostic of a stable CRIB:PDZ interface. Notably, apo CRIB-PDZ ${ }^{\mathrm{Q} 144 \mathrm{C} / \mathrm{L} 164 \mathrm{C}} \mathrm{R}_{2}$ dispersion measurements yielded a similar exchange profile to apo PDZ ${ }^{156-255}$ and apo CRIB-PDZ ${ }^{130-255}$ (Figure S2D). In agreement with our findings, equilibrium unfolding and deuterium exchange data indicate that CRIBPDZ ${ }^{\mathrm{Q} 144 C / L 164 C}$ is markedly more stable $\left(\Delta G_{\mathrm{unf}}=5.1 \pm 0.1 \mathrm{kcal} / \mathrm{mol}\right.$, $\Delta G_{\mathrm{HX}}=4.9 \pm 0.1 \mathrm{kcal} / \mathrm{mol}$ ) than CRIB-PDZ ${ }^{130-255}$ (Figure S2C). Therefore, only interactions with a flexible CRIB domain promote instability in the PDZ domain even when peptide is bound in the PDZ ligand binding pocket.

\section{Discussion and Conclusions}

Allosteric activation of the Par-6 CRIB-PDZ module by Cdc42 is transmitted to the peptide binding site by a dipeptide switch that interconverts the side chains of L164 and K165 (Figure 1). ${ }^{11}$ Liganddependent changes in the pattern of paramagnetic broadening (Figure 2) demonstrated that peptide binding displaces L164 from the carboxylate binding pocket, thereby switching to the high affinity L164 'out'/K165 'in' configuration observed in Par- 6 crystal structures and other PDZ domains. We measured ${ }^{15} \mathrm{~N}$ relaxation dispersion expecting conformational exchange effects $\left(R_{\mathrm{ex}}\right)$ near the L/K switch but instead found that residues throughout the PDZ domain fluctuate at a common rate of $\sim 1600 \mathrm{~s}^{-1}$. The frequency of conformational exchange may be correlated with dipeptide switch interconversion, but the effects extend well beyond the $\beta_{1-2}$ loop, perhaps representing a domain-wide process. The estimated rates of global folding and unfolding (Figure 4) were too slow ( $k_{\mathrm{ex}} \sim 65 \mathrm{~s}^{-1}$ ) to account for the observed $R_{\mathrm{ex}}$, but additional measurements helped to identify a structural element within the PDZ domain that undergoes a concerted millisecond time scale rearrangement.

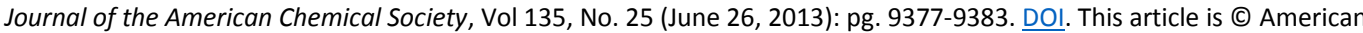
Chemical Society and permission has been granted for this version to appear in e-Publications@Marquette. American Chemical Society does not grant permission for this article to be further copied/distributed or hosted elsewhere without the express permission from American Chemical Society. 


\section{$R_{2}$ Dispersions in Par-6 PDZ Report on Partial Unfolding}

Native ${ }^{1} \mathrm{H}-{ }^{2} \mathrm{D}$ exchange data identified a set of residues protected in both CRIB-PDZ ${ }^{130-255}$ and PDZ ${ }^{156-255}$ (K165, I195, L212, E220, V221, I224, V226, V234, M237, M238, V239, and I246) (Figure $5)$ which delineate a stable 'folding core'. This is important for two reasons: First, we observed widespread $R_{\mathrm{ex}}$ throughout the PDZ domain in all apo states of Par-6, (Figure 2), but careful inspection of the nonexchanging residues in each apo construct reveals a striking overlap with the stable PDZ core (Figure 7A). In contrast, exchanging residues are located in or adjacent to the $\beta_{1-2}$ loop, which encompasses the dipeptide switch, and the long $\beta_{2-3}$ hairpin (Figure 3C). Second, two residues in the 'folding core' group (V234 and M237) display a linear dependence of $\Delta G_{H X}$ at low guanidine concentrations, a sign of nearby partial unfolding in the structure (Figure 7B). ${ }^{8,30}$ This is consistent with previous reports utilizing $\varphi$-value analysis to determine unfolding transition-state compositions of PDZ domains. ${ }^{28}$ They report that the final folding barrier (TS2) involves docking of the $\beta_{2-3}$ finger into a folding core that includes the $a_{2}$ helix. Taken together, our measurements of Par- 6 backbone dynamics and unfolding parameters are consistent with native-state access to an on-pathway unfolding intermediate similar to that observed for several other PDZ domains. Dissociation of the $\beta_{2-3}$ finger from the rest of the PDZ core would give the $\beta_{1-2}$ loop additional flexibility and provides an opportunity for isomerization of the dipeptide switch.

Journal of the American Chemical Society, Vol 135, No. 25 (June 26, 2013): pg. 9377-9383. DOI. This article is (C) American Chemical Society and permission has been granted for this version to appear in e-Publications@Marquette. American Chemical Society does not grant permission for this article to be further copied/distributed or hosted elsewhere without the express permission from American Chemical Society. 
A

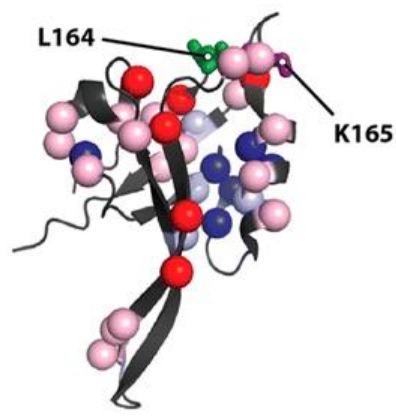

B

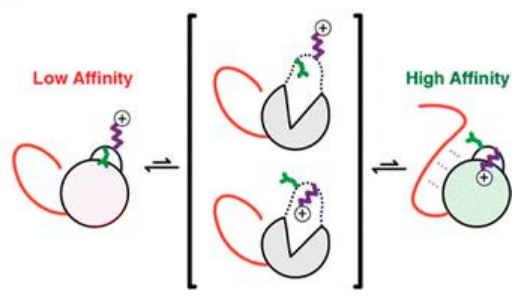

Figure 7. Segregation of dynamic and stable subdomains suggests a possible mode of partial PDZ unfolding. (A) Pink spheres indicate residues with $R_{\mathrm{ex}} \geq 2 \mathrm{~s}^{-1}$ in CRIBPDZ ${ }^{130-255}$ and PDZ ${ }^{156-255}$ and red spheres indicate $R_{\mathrm{ex}} \geq 2 \mathrm{~s}^{-1}$ and those residues globally fit for both. Light-blue and navy spheres indicate residues with detectable protection factors (the "folding core"), where the latter concurrently lack $\mathrm{R}_{2}$ dispersions. One residue, V239, is colored violet because it has a detectable protection factor and significant $R_{\mathrm{ex}}$. (B) Schematic of $\mathrm{L} / \mathrm{K}$ switch isomerization via a partial unfolding mechanism. Residue L164 is colored green, and K165 is colored purple. Brackets surrounding two center diagrams represent putative energetically equivalent states in the folding intermediate state. CRIB domain is colored red.

\section{Cdc42-GTP Activation of the CRIB-PDZ}

In the absence of Cdc42-GTP (or a high concentration of peptide ligand), the CRIB-PDZ module is predominantly in the low-affinity (L164 'in' /K165 'out') L/K switch configuration. Because Cdc42-GTP promotes isomerization of the $L / K$ switch, which requires partial PDZ unfolding, we considered the possibility that the GTPase could also drive the unfolding process. However, NMR and crystallographic analysis showed that Cdc42 binds preferentially to the CRIB-PDZ module in the high-affinity (L164 'out' /K165 'in') conformation; ${ }^{11,12,36}$ formation of the CRIB:PDZ interface is incompatible with the lowaffinity arrangement. Because Cdc42-GTP binding promotes folding of the CRIB and stabilizes the CRIB:PDZ interface, it seems unlikely that the GTPase catalyzes PDZ unfolding. Instead, we propose a model in which allosteric activation of the Par- $6 \mathrm{~L} / \mathrm{K}$ switch involves spontaneous partial unfolding of the PDZ domain on microsecondmillisecond ( $\mu s-\mathrm{ms}$ ) time scales. In this model, Cdc42-GTP binding 
activates Par- 6 by shifting a preexisting CRIB-PDZ conformational equilibrium toward the high-affinity configuration of the L/K switch.

\section{Marginal Thermodynamic Stability As a Functional Advantage}

Evolutionary pressure tunes proteins for efficient function over all else, provided that sufficient folding energy is preserved. ${ }^{37}$ As a consequence, thermodynamic stability of a protein structure will be compromised in order to gain functionality, as has been shown in T7 lysozyme. ${ }^{38}$ This reciprocal relationship between thermodynamic stability and neofunctionalization was recently demonstrated for another member of the PDZ family. Smith et al. engineered a PKA substrate site into the ERBIN PDZ domain but found that efficient phosphorylation also required other destabilizing mutations. ${ }^{39}$ The increase in flexibility, they concluded, was necessary to permit PKA to seize its target sequence for enzymatic activity. ${ }^{39}$ We observe a similar reciprocal stability-function relationship in the Par-6 PDZ, where the modest margin of folding stability $\left(\Delta G_{\text {unfold }}=3.4 \mathrm{kcal} / \mathrm{mol}\right.$ ) ensures frequent access to a partially unfolded state for dipeptide switch interconversion. Attachment of the CRIB domain further destabilizes the PDZ but increases its affinity for the VKESLV peptide. We conclude that, in the absence of Cdc42-GTP (or a high concentration of peptide ligand), transient interactions with the disordered CRIB enhance peptide ligand binding by selectively destabilizing the low-affinity PDZ conformation, thereby shifting the L/K switch equilibrium toward the high-affinity configuration.

\section{Functional Unfolding in the Native State}

Protein folding is an equilibrium process, and the unfolded state is significantly populated $(>1 \%)$ in a protein of marginal stability ( $\Delta G_{\text {unfold }}<2.8 \mathrm{kcal} / \mathrm{mol}$ ) at $25^{\circ} \mathrm{C}$. We speculate that functional advantages derived from protein destabilization often reflect a requirement for native-state access to an unfolded region of the conformational energy landscape. Certain proteins undergo large-scale unfolding motions to undertake their biological roles. Lymphotactin, a prototypical 'metamorphic' protein, interconverts between a monomer with the canonical chemokine fold that activates its GPCR target and

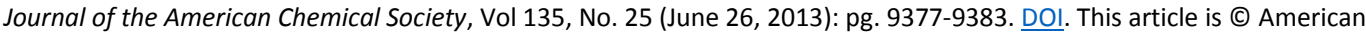
Chemical Society and permission has been granted for this version to appear in e-Publications@Marquette. American Chemical Society does not grant permission for this article to be further copied/distributed or hosted elsewhere without the express permission from American Chemical Society. 
an unrelated all- $\beta$ dimeric structure that binds extracellular matrix glycosaminoglycans. ${ }^{40-42}$ The need for an unfolding transition is apparent when access to different functional states involves a reversible global structural rearrangement. However, many proteins exchange between closely related conformations where native-state unfolding does not appear necessary. Our results suggest that partial unfolding of the Par-6 PDZ, perhaps populating an evolutionarily conserved ${ }^{23,29,30}$ intermediate, is required for allosteric activation of a conformational switch that modulates ligand binding affinity. This is a direct demonstration of allosteric PDZ regulation by an unfolding transition, and we speculate that native-state unfolding contributes to the function of many other signaling proteins as well.

\section{Materials and Methods}

\section{Mutagenesis, Protein Expression, and Purification}

Drosophila melanogaster Par-6 proteins were produced as previously described. ${ }^{12}$ CRIB-PDZQ144C/L164C variant purification proceeded as previously described. ${ }^{11}$ Creation of the CRIB-PDZ ${ }^{\text {L164C }}$ variant utilized QuikChange II Site-Directed Mutagenesis Kit (Stratagene) and verified by DNA sequencing (Retrogen). All proteins were expressed and purified as previously described. ${ }^{11,12,43}$ Final protein purity was measured as $>99 \%$ by SDS-PAGE and MALDI-TOF spectroscopy.

\section{NMR Spectroscopy}

NMR experiments were carried out at $25^{\circ} \mathrm{C}$ on a Bruker Avance $600 \mathrm{MHz}$ or Bruker Avance III $500 \mathrm{MHz}$ spectrometer equipped with a TCI CryoProbe. All NMR samples contained 0.75-1.25 mM ${ }^{15} \mathrm{~N}$-labeled protein and were prepared in $90 \% \mathrm{H}_{2} \mathrm{O} / 10 \% \mathrm{D}_{2} \mathrm{O}$ containing $20 \mathrm{mM}$ $\mathrm{NaHPO}_{4}, 20 \mathrm{mM} \mathrm{NaAc} \mathrm{pH}$ 5.5, $50 \mathrm{mM} \mathrm{NaCl}$, and $0.05 \%$ sodium azide. NMR data were processed with the NMRPipe software package. ${ }^{44}$ The Sparky program ${ }^{45}$ was used for peak intensity determination and tabulation.

Journal of the American Chemical Society, Vol 135, No. 25 (June 26, 2013): pg. 9377-9383. DOI. This article is (c) American Chemical Society and permission has been granted for this version to appear in e-Publications@Marquette. American Chemical Society does not grant permission for this article to be further copied/distributed or hosted elsewhere without the express permission from American Chemical Society. 


\section{Paramagnetic Relaxation Enhancement}

PRE experiments proceeded as previously detailed, ${ }^{46}$ except that purified ${ }^{15} \mathrm{~N}$ CRIB-PDZ ${ }^{\mathrm{L} 164 \mathrm{C}}$ protein was incubated overnight at $4{ }^{\circ} \mathrm{C}$ with a 5-fold molar excess of MTSL (Toronto Research Chemicals) in a buffered solution containing $20 \mathrm{mM} \mathrm{NaHPO} 4 \mathrm{pH} 7.5,20 \mathrm{mM} \mathrm{NaAc}$, and $50 \mathrm{mM} \mathrm{NaCl}$, and excess free thiol was removed by desalting column. Nitroxide radical quenching was accomplished by adding $5 \mu \mathrm{L}$ of buffer-matched ascorbic acid solution to paramagnetic samples and incubating for $12 \mathrm{~h}$ at $25^{\circ} \mathrm{C}$ to achieve full spin label quenching. ${ }^{1} \mathrm{H}-$ ${ }^{15} \mathrm{~N}$ HSQC NMR spectra were measured before and after ascorbate quenching to obtain peak intensity values for ${ }^{15} \mathrm{~N}$ CRIB-PDZ ${ }^{130-255}$. Tabluation of peak intensities from paramagnetic and diamagnetic spectra allowed determination of paramagnetic relaxation caused directly by MTSL contact with the C164 side chain. iPRE values were calculated as

$$
\mathrm{iPRE}=1-\left(I_{\mathrm{para}} / I_{\mathrm{dia}}{ }^{*} \mathrm{DF}\right)
$$

where DF represents the dilution factor upon addition of ascorbic acid. An iPRE value near 0 indicates a noncontacted residue, and a value near 1 indicates a backbone amide that makes close, consistent contact with the MTSL label and reports on full bleaching of the NMR signal in paramagnetic conditions.

\section{$R_{2}$ Backbone Dispersion Experiments}

Measurements of the transverse relaxation rate constant of ${ }^{15} \mathrm{~N}$ amide nuclei proceeded as previously described. ${ }^{1}$ Relaxation rate measurements were performed at $83(6), 100(6), 125(6), 151$ (6), 175 (5), 200 (6), 250 (6), 300 (6), 384 (5), and 555 (6) Hz (effective $B_{1}$ field frequency). A reference experiment (zero relaxation delay) was repeated 8 times for a total of 62 measurements per experiment. Data collection and analysis proceeded as previously described, ${ }^{19}$ except that rCCPMG data sets were acquired at 15 and $25^{\circ} \mathrm{C}$ at 11.7 and 14.1 $T$ for all apo and VKESLV-bound proteins. VKESLV:protein ratio was $\geq 6: 1$ for all bound experiments to ensure full binding. 


\section{Stopped-Flow Experiments for Determining Rates of GnHCl-Induced Unfolding}

Stopped-flow kinetic experiments were performed as previously detailed. ${ }^{42}$ All experiments used a final concentration of $25 \mu \mathrm{M}$ protein in solution. Curve fitting and data analysis proceeded as previously described, ${ }^{42}$ except that 5-10 traces per sample point were averaged to determine kinetic rate constants. For folding measurements, a $1: 1$ dilution of buffered protein and $\mathrm{GnHCl}$ solution with a matched blank buffer was used. For unfolding measurements, 1:1 dilution of a buffered protein solution with a buffered $\mathrm{GnHCl}$ solution was used. Buffered solutions contained $25 \mathrm{mM} \mathrm{NaHPO}_{4} \mathrm{pH}$ 5.5, $20 \mathrm{mM} \mathrm{NaAc}$, and $50 \mathrm{mM} \mathrm{NaCl}$. All unfolding experiments were conducted by rapid mixing with $\mathrm{GnHCl}$ at multiple final concentrations $(0.3,0.35,0.4,0.5$, $0.6,1.0,1.5,2.0,2.75,3.0,3.25$, and $3.5 \mathrm{M}$ ).

\section{Native ${ }^{1} H-{ }^{2} D$ Exchange Experiments}

Native deuterium exchange experiments were collected as serial ${ }^{1} \mathrm{H}-{ }^{15} \mathrm{~N}$ HSQC spectra immediately following dilution of fully protonated, lyophilized, and ${ }^{15} \mathrm{~N}$-labeled proteins. Data analysis proceeded as previously described. ${ }^{32,35}$ Experimental conditions for all native exchange took place at $\mathrm{pD} 5.9,25^{\circ} \mathrm{C} .{ }^{1} \mathrm{H}-{ }^{2} \mathrm{D}$ exchange vs [denaturant] experiments were analyzed as previously detailed, $8,30,31$ except that all NMR experiments took place at pD 5.9, $10^{\circ} \mathrm{C}$. Guanidine $\mathrm{HCl}$ concentrations used were $0.1,0.2,0.3$, and $0.4 \mathrm{M}$.

\section{Equilibrium Unfolding Experiments and Determination of Unfolding Free Energies}

Measurements were performed as previously described, ${ }^{42}$ except that the excitation wavelength of $274 \mathrm{~nm}$ was used with a bandwidth of $6 \mathrm{~nm}$ for tyrosine fluorescence. All proteins displayed a $\lambda_{\max }$ at 304 $\pm 2 \mathrm{~nm}$. Buffered (20 mM Na${ }_{2} \mathrm{HPO}_{4}, 20 \mathrm{NaAc} \mathrm{pH} 5.5,50 \mathrm{mM} \mathrm{NaCl}$ ) guanidine $\mathrm{HCl}$ stocks were used for all unfolding measurements. Unfolding curves were recorded by monitoring fluorescence intensity at $304 \mathrm{~nm}$ as a function of guanidine concentration. Data analysis proceeded as previously detailed. 42 
NOT THE PUBLISHED VERSION; this is the author's final, peer-reviewed manuscript. The published version may be accessed by following the link in the citation at the bottom of the page.

\section{Supporting Information}

iPRE values by residue, VKESLV:CRIB-PDZ ${ }^{130-255} \mathrm{R}_{2}$ dispersion measurements, apo CRIB-PDZ $144 C / L 164 C$ R2 dispersion measurements, CRIB-PDZ $144 C / L 164 C$ unfolding analysis, global fitted population tables, and $\Delta G_{H X}$ values at multiple guanidine concentrations. This material is available free of charge via the Internet at http://pubs.acs.org.

The authors declare no competing financial interest.

\section{Acknowledgment}

We would like to thank Dr. Blake Hill (Medical College of Wisconsin) for critical reading of this manuscript and Dr. Jim Feix (Medical College of Wisconsin) for assistance with spin labeling. This work was supported by NIH grant R01 AI058072.

\section{References}

${ }^{1}$ Buhrman, G.; O'Connor, C.; Zerbe, B.; Kearney, B. M.; Napoleon, R.; Kovrigina, E. A.; Vajda, S.; Kozakov, D.; Kovrigin, E. L.; Mattos, C. J. Mol. Biol. 2011, 413, 773

${ }^{2}$ Villali, J.; Kern, D. Curr. Opin. Chem. Biol. 2010, 14, 636

${ }^{3}$ Anfinsen, C. B. Biochem. J. 1972, 128, 737

${ }^{4}$ Volkman, B. F.; Lipson, D.; Wemmer, D. E.; Kern, D. Science 2001, 291, 2429

5Zhang, J.; Sapienza, P. J.; Ke, H.; Chang, A.; Hengel, S. R.; Wang, H.;

Phillips, G. N.; Lee, A. L. Biochemistry 2010, 49, 9280

${ }^{6}$ Mauldin, R. V.; Carroll, M. J.; Lee, A. L. Structure 2009, 17, 386

${ }^{7}$ Kern, D.; Zuiderweg, E. R. Curr. Opin. Chem. Biol. 2003, 13, 748

${ }^{8} \mathrm{Vu}$, N. D.; Feng, H.; Bai, Y. Biochemistry 2004, 43, 3346

${ }^{9}$ Went, H. M.; Benitez-Cardoza, C. G.; Jackson, S. E. FEBS Lett. 2004, 567, 333

${ }^{10}$ Serrano, A. L.; Bilsel, O.; Gai, F. J. Phys. Chem. B 2012, 116, 10631

${ }^{11}$ Whitney, D. S.; Peterson, F. C.; Volkman, B. F. Structure 2011, 19, 1711

${ }^{12}$ Peterson, F. C.; Penkert, R. R.; Volkman, B. F.; Prehoda, K. E. Mol. Cell 2004, 13, 665

${ }^{13}$ Horikoshi, Y.; Suzuki, A.; Yamanaka, T.; Sasaki, K.; Mizuno, K.; Sawada, H.; Yonemura, S.; Ohno, S. J. Cell Sci. 2009, 122, 1595

${ }^{14}$ Penkert, R. R.; DiVittorio, H. M.; Prehoda, K. E. Nat. Struct. Mol. Biol. 2004, 11,1122

${ }^{15}$ Kempf, J. G.; Loria, J. P. Methods Mol. Biol. 2004, 278, 185

${ }^{16}$ Palmer, A. G., III Curr. Opin. Chem. Biol. 1997, 7, 732

Journal of the American Chemical Society, Vol 135, No. 25 (June 26, 2013): pg. 9377-9383. DOI. This article is (C) American Chemical Society and permission has been granted for this version to appear in e-Publications@Marquette. American Chemical Society does not grant permission for this article to be further copied/distributed or hosted elsewhere without the express permission from American Chemical Society. 
NOT THE PUBLISHED VERSION; this is the author's final, peer-reviewed manuscript. The published version may be accessed by following the link in the citation at the bottom of the page.

${ }^{17}$ Palmer, A. G., III; Kroenke, C. D.; Loria, J. P. Methods Enzymol. 2001, 339, 204

${ }^{18}$ Korzhnev, D. M.; Salvatella, X.; Vendruscolo, M.; Di Nardo, A. A.; Davidson, A. R.; Dobson, C. M.; Kay, L. E. Nature 2004, 430, 586

${ }^{19}$ O'Connor, C.; Kovrigin, E. L. Biochemistry 2008, 47, 10244

${ }^{20}$ Meinhold, D. W.; Wright, P. E. Proc. Natl. Acad. Sci. U.S.A. 2011, 108, 9078

${ }^{21}$ Tollinger, M.; Skrynnikov, N. R.; Mulder, F. A.; Forman-Kay, J. D.; Kay, L.

E. J. Am. Chem. Soc. 2001, 123, 11341

${ }^{22}$ Gianni, S.; Ivarsson, Y.; Jemth, P.; Brunori, M.; Travaglini-Allocatelli, C. Biophys. Chem. 2007, 128, 105

${ }^{23}$ Gianni, S.; Calosci, N.; Aelen, J. M.; Vuister, G. W.; Brunori, M.; TravagliniAllocatelli, C. Protein Eng., Des. Sel. 2005, 18, 389

${ }^{24}$ Chi, C. N.; Gianni, S.; Calosci, N.; Travaglini-Allocatelli, C.; Engstrom, K.; Jemth, P. FEBS Lett. 2007, 581, 1109

${ }^{25}$ Gianni, S.; Ivarsson, Y.; De Simone, A.; Travaglini-Allocatelli, C.; Brunori, M.; Vendruscolo, M. Nat. Struct. Mol. Biol. 2010, 17, 1431

${ }^{26}$ Calosci, N.; Chi, C. N.; Richter, B.; Camilloni, C.; Engstrom, A.; Eklund, L.; Travaglini-Allocatelli, C.; Gianni, S.; Vendruscolo, M.; Jemth, P. Proc. Natl. Acad. Sci. U.S.A. 2008, 105, 19241

${ }^{27}$ Gianni, S.; Brunori, M.; Jemth, P.; Oliveberg, M.; Zhang, M. Biochemistry $2009,48,11825$

${ }^{28}$ Gianni, S.; Geierhaas, C. D.; Calosci, N.; Jemth, P.; Vuister, G. W.; Travaglini-Allocatelli, C.; Vendruscolo, M.; Brunori, M. Proc. Natl. Acad. Sci. U.S.A. 2007, 104, 128

${ }^{29}$ Ivarsson, Y.; Travaglini-Allocatelli, C.; Jemth, P.; Malatesta, F.; Brunori, M.; Gianni, S. J. Biol.Chem. 2007, 282, 8568

${ }^{30}$ Feng, H.; Vu, N. D.; Bai, Y. J. Mol. Biol. 2005, 346, 345

${ }^{31}$ Chamberlain, A. K.; Handel, T. M.; Marqusee, S. Nat. Struct. Biol. 1996, 3, 782

${ }^{32}$ Bai, Y.; Milne, J. S.; Mayne, L.; Englander, S. W. Proteins 1993, 17, 75

${ }^{33}$ Raschke, T. M.; Marqusee, S. Curr. Opin. Biotechnol. 1998, 9, 80

${ }^{34}$ Bartlett, A. I.; Radford, S. E. Nat. Struct. Mol. Biol. 2009, 16, 582

${ }^{35}$ Nishimura, C.; Dyson, H. J.; Wright, P. E. Proc. Natl. Acad. Sci. U.S.A. 2005, 102,4765

${ }^{36}$ Garrard, S. M.; Capaldo, C. T.; Gao, L.; Rosen, M. K.; Macara, I. G. ; Tomchick, D. R. EMBO J. 2003, 22, 1125

37Pauling, L.; Pressman, D.; Campbell, D. H. Science 1943, 98, 263

${ }^{38}$ Shoichet, B. K.; Baase, W. A.; Kuroki, R.; Matthews, B. W. Proc. Natl. Acad. Sci. U.S.A. 1995, 92, 452

${ }^{39}$ Smith, C. A.; Shi, C. A.; Chroust, M. K.; Bliska, T. E.; Kelly, M. J.; Jacobson, M. P.; Kortemme, T. Structure 2012, 21, 54

${ }^{40}$ Volkman, B. F.; Liu, T. Y.; Peterson, F. C. Methods Enzymol. 2009, 461, 51

Journal of the American Chemical Society, Vol 135, No. 25 (June 26, 2013): pg. 9377-9383. DOI. This article is (c) American Chemical Society and permission has been granted for this version to appear in e-Publications@Marquette. American Chemical Society does not grant permission for this article to be further copied/distributed or hosted elsewhere without the express permission from American Chemical Society. 
NOT THE PUBLISHED VERSION; this is the author's final, peer-reviewed manuscript. The published version may be accessed by following the link in the citation at the bottom of the page.

${ }^{41}$ Tuinstra, R. L.; Peterson, F. C.; Kutlesa, S.; Elgin, E. S.; Kron, M. A.;

Volkman, B. F. Proc. Natl. Acad. Sci. U.S.A. 2008, 105, 5057

${ }^{42}$ Tyler, R. C.; Murray, N. J.; Peterson, F. C.; Volkman, B. F. Biochemistry 2011, 50, 7077

${ }^{43}$ Volkman, B. F.; Prehoda, K. E.; Scott, J. A.; Peterson, F. C.; Lim, W. A. Cell 2002, 111, 565

${ }^{44}$ Delaglio, F.; Grzesiek, S.; Vuister, G. W.; Zhu, G.; Pfeifer, J.; Bax, A. J. Biomol. NMR 1995, 6, 277

${ }^{45}$ Goddard, T. D.; Kneller, D. G.SPARKY 3, University of California, San Francisco.

${ }^{46}$ Gillespie, J. R.; Shortle, D. J. Mol. Biol. 1997, 268, 170

Journal of the American Chemical Society, Vol 135, No. 25 (June 26, 2013): pg. 9377-9383. DOI. This article is (C) American Chemical Society and permission has been granted for this version to appear in e-Publications@Marquette. American Chemical Society does not grant permission for this article to be further copied/distributed or hosted elsewhere without the express permission from American Chemical Society. 